\title{
IPSILATERAL OPHTHALMIC ARTERY STENOSIS IN AMAUROSIS FUGAX: A CASE REPORT
}

\author{
Referano Agustiawan ${ }^{1}$, Ferdy Iskandar², Muhammad Ikhsan Mokoagow ${ }^{3,4}$, Firman Hendrik ${ }^{5}$, Kanovnegara ${ }^{6}$ \\ ${ }^{1}$ Ophthalmologist, Jakarta Eye Center Hospitals and Clinics, Jakarta, Indonesia \\ ${ }^{2}$ General Practitioner, Pondok Indah - Puri Indah Hospital, Jakarta, Indonesia \\ ${ }^{3}$ Internist, Pondok Indah - Puri Indah Hospital, Jakarta, Indonesia \\ ${ }^{4}$ Internist, Jakarta Eye Center Hospitals and Clinics, Jakarta, Indonesia \\ ${ }^{5}$ Neurologist, Pondok Indah - Puri Indah Hospital, Jakarta, Indonesia \\ ${ }^{6}$ Radiologist, Pondok Indah - Puri Indah Hospital, Jakarta, Indonesia
}

\section{ABSTRACT}

Introduction: Amaurosis fugax is caused by an abrupt reduction of blood flow to the retina. Determining the etiology of amaurosis fugax should ensure proper management.

Case Report: A 47-year-old female patient complaint about the first episode of sudden vision loss in her right eye and was referred to our hospital. The vision loss resolved spontaneously, however, we found a $3 \mathrm{~mm}$ long stenosis at her right ophthalmic artery during magnetic resonance angiography. She had clinical histories of untreated hypertension and dyslipidemia. Transient ischemic attack (TIA) was suspected and unfractionated heparin, aspirin, antihypertensive agent, and statin were given. Treatments were maintained, the symptoms had not recurred in the following 6 months after the event.

Discussion: Stenosis of the ophthalmic artery is very rare. It occurs in approximately $2 \%$ of patient suffering from amaurosis fugax. In our case, stenosis of the right ophthalmic artery due to thromboembolism might cause retinal ischemia leading to a transient visual loss.

Conclusion: This case suggests stenosis of ophthalmic artery as the cause of amaurosis fugax.

Keywords: amaurosis fugax, ipsilateral, ophthalmic artery, stenosis

Cite This Article: AGUSTIAWAN, Referano et al. Ipsilateral Ophthalmic Artery Stenosis in Amaurosis Fugax: A Case Report. International Journal of Retina, [S.I.], v. 4, n. 1, p. 78, feb. 2021. ISSN 2614-8536. Available at: <https://www.ijretina.com/index.php/ijretina/article/view/131>. Date accessed: 22 feb. 2021 . doi: https://doi.org/10.35479/ijretina.2021.vol004.iss001.131.

${ }^{*}$ Correspondence to:

Ferdy Iskandar,

Pondok Indah - Puri Indah Hospital,

Jakarta, Indonesia

iskandar.ferdy@gmail.com,

\section{INTRODUCTION}

Amaurosis fugax
describes monocular or
binocular loss of vision,
typically lasting seconds
to minutes. ${ }^{1,2}$ This

symptom is generally caused by a manifestation of thromboembolic event in which atherosclerotic debris originating in the carotid artery or the aortic arch temporarily disrupts blood flow in the branch or central retinal arteriolar network. ${ }^{2,3}$ Immediately treating a patient with amaurosis fugax in whom aortic or carotid atherosclerosis is detected with an anti-platelet agent and a statin are consistent established guidelines. ${ }^{4}$ Migraine, retinal detachment, optic disc drusen or papilledema, glaucoma, emboli from thoracic arteries or external carotid, mitral valve prolapse, hypercoagulable state, giant cell arteritis (GCA), vasospasm, postural hypotension, acute sharp pain, nose-blowing, and sensitivity to cold, however, can also be the cause of amaurosis fugax. ${ }^{4-5}$ Therefore, proper management depends on the underlying cause.

\section{CASE REPORT}

A 47-year-old female patient presented with the first episode of sudden vision loss in her right eye for approximately 30 minutes, prior to reaching the hospital. She experienced no headache. She had clinical histories 
of hypertension and dyslipidemia, and was not under medical therapy. She was fully alert, and visual acuity of both eyes had returned to $20 / 20$ by the time of initial density lipoprotein/HDL (55 mg/dL). Coagulation parameters including $\mathrm{d}$-dimer, fibrinogen, and platelet aggregation studies were within normal limits. Other
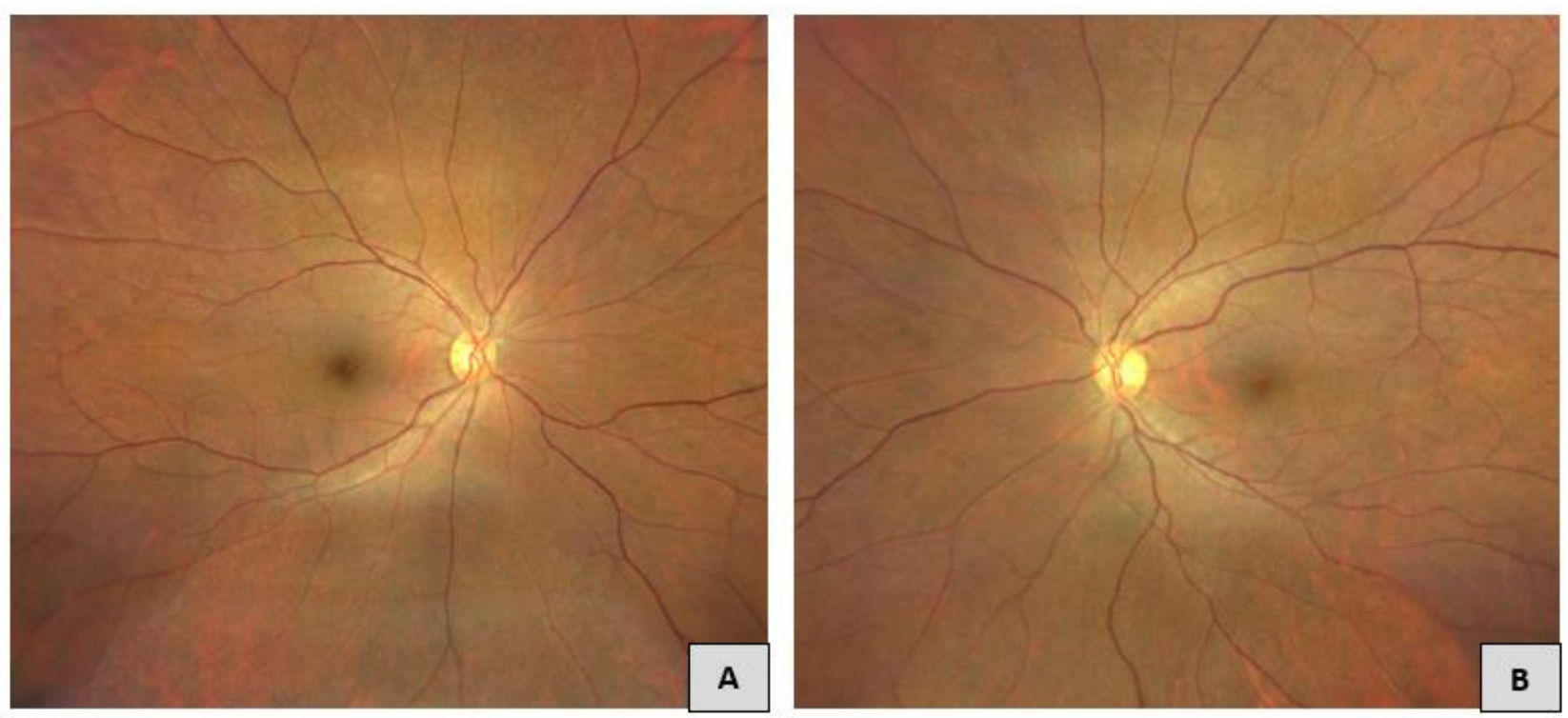

Figure 1. Normal color fundus photograph of right eye (A) and left eye (B).

clinical examination. Her blood pressure was 158/77 $\mathrm{mmHg}$. Slit-lamp and ophthalmoscopy examination findings were unremarkable (Figure 1). Intraocular pressure (IOP) in the right eye and left eye was 19.7 $\mathrm{mmHg}$ and $18.0 \mathrm{mmHg}$ respectively, and was measured neurological and hematological parameters were within normal ranges. Magnetic resonance angiography revealed a $3 \mathrm{~mm}$ long stenosis at the right ophthalmic artery (Figure 2 and 3). Optical coherence tomography (OCT) examination was within normal limits (Figure 4

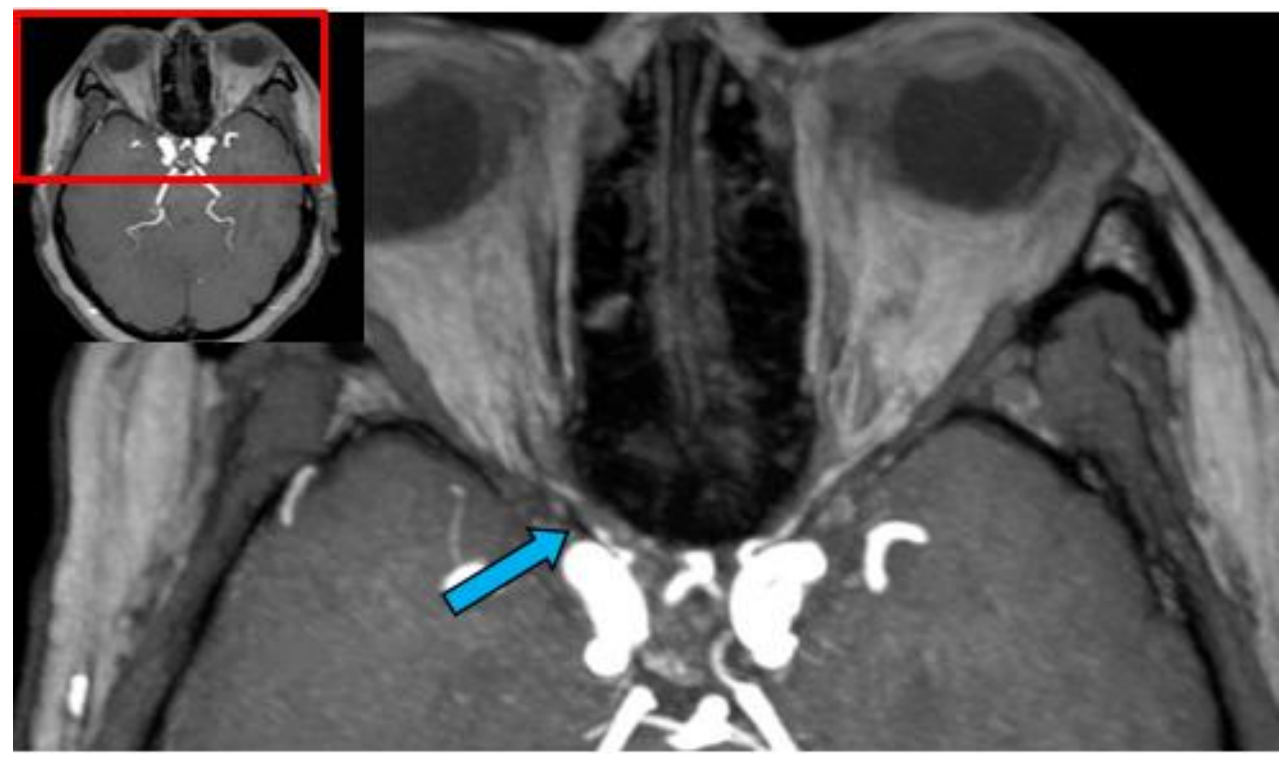

Figure 2. MR angiography, blue arrow demonstrated a 3mm-long stenosis at the right ophthalmic artery (axial image).

with applanation tonometry. Laboratory studies demonstrated high levels of total cholesterol (222 $\mathrm{mg} / \mathrm{dL})$, low-density lipoprotein/LDL (139 mg/dL), triglycerides (169 mg/dL), and normal level of high- and 5). The amaurosis fugax resolved spontaneously. We treated her case as retinal transient ischemic attack (TIA), and 
she received unfractionated heparin during hospitalization. Aspirin, candesartan, and rosuvastatin regiments were initiated promptly. amaurosis fugax. During the episode, fundoscopy revealed a cholesterol crystal in the lower temporal

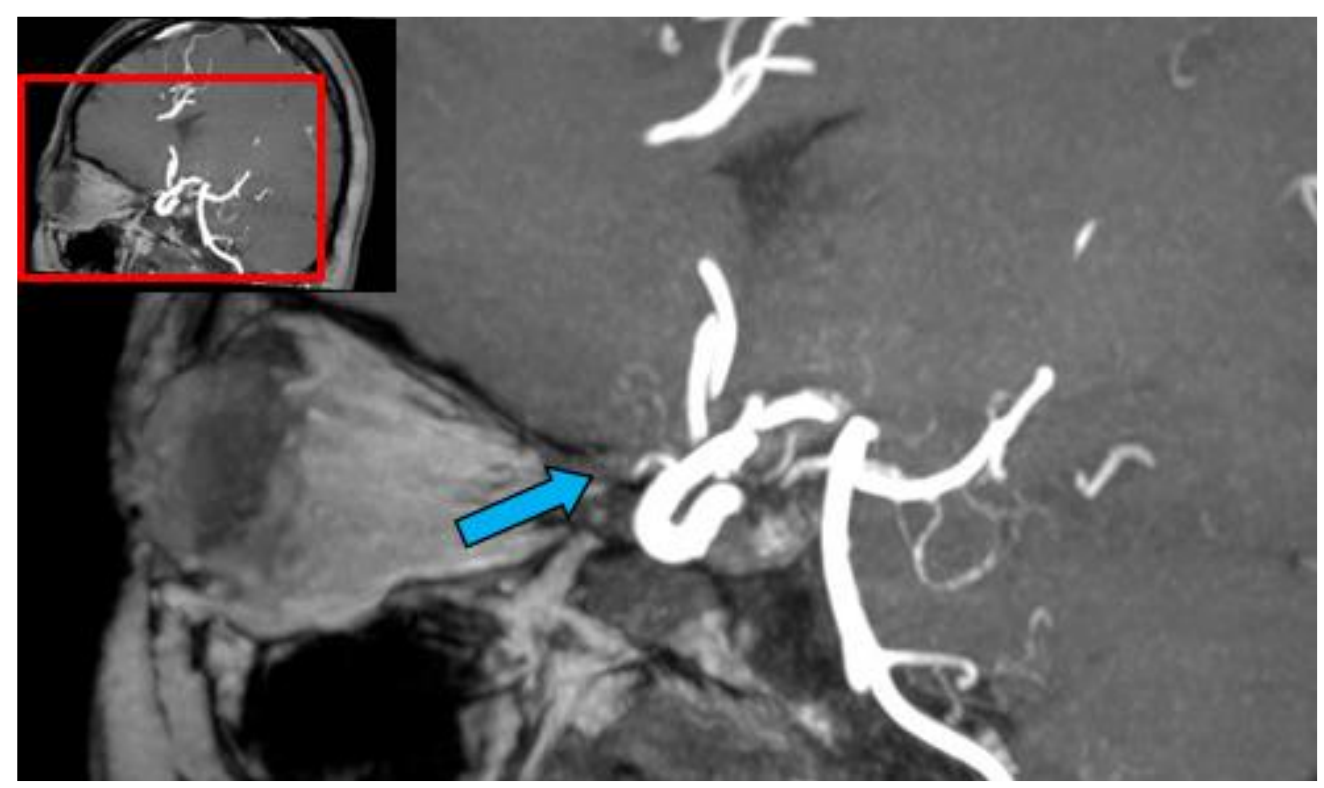

Figure 3. MR angiography, blue arrow demonstrated a 3mm-long stenosis at the right ophthalmic artery (sagittal image).

\section{DISCUSSION}

Braat et al. $^{6}$ reported a patient with isolated ophthalmic artery stenosis and one episode of branch of the central retinal artery with hemorrhage of the macula. Micro-embolism of the ophthalmic artery seemed to cause amaurosis

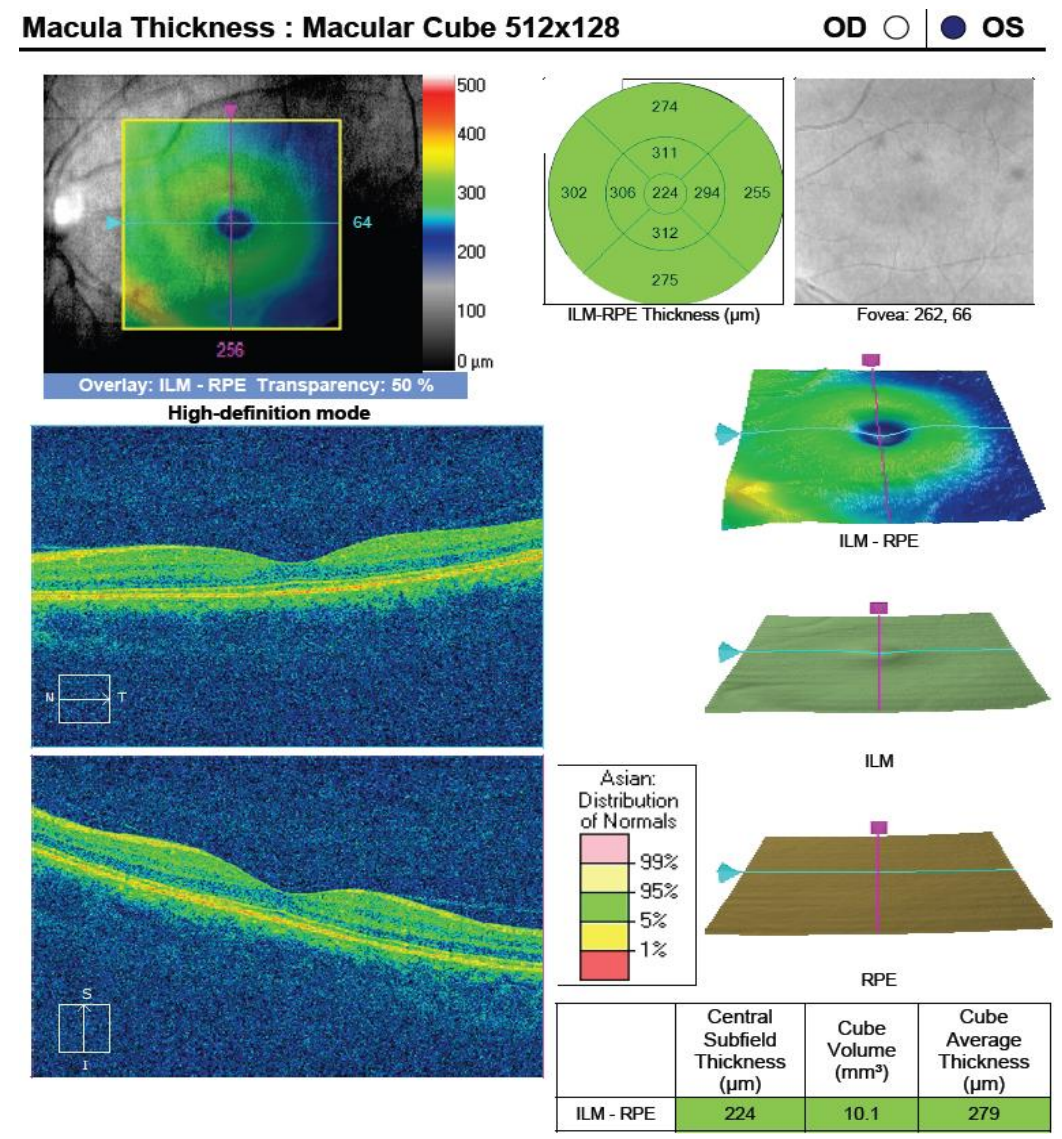

Figure 4. Normal Optical Coherence Tomography (OCT) of the right eye (OD) 
fugax, and anticoagulation was maintained successfully for preventing attacks. Nakajima et al. ${ }^{7}$ postulated that high frequency of amaurosis fugax attacks in the ophthalmic artery stenosis could be explained by platelet hyperaggregability since aspirin proved effective in preventing attacks. Cerebral angiography may show focal stenosis at the origin of the central retinal artery or ophthalmic artery. ${ }^{8}$ Stenosis of the ophthalmic artery is very rare. According to a previous study, the prevalence of ophthalmic artery stenosis is approximately $2 \%$ in patients suffering from amaurosis fugax. ${ }^{5}$ transient visual loss. Amaurosis fugax and TIA are clinical conditions with shared etiology that both increase the risk of ischemic stroke, as the patient had several risk factors, notably dyslipidemia and hypertension. The treatment for retinal TIA is similar to that of cerebral $\mathrm{TIA}^{9}$, therefore unfractionated heparin and aspirin were administered along with candesartan and rosuvastatin to manage the underlying conditions.

TIA suspected patients should be evaluated as soon as possible after an event. If retinal TIA is present within 72 hours, American Heart

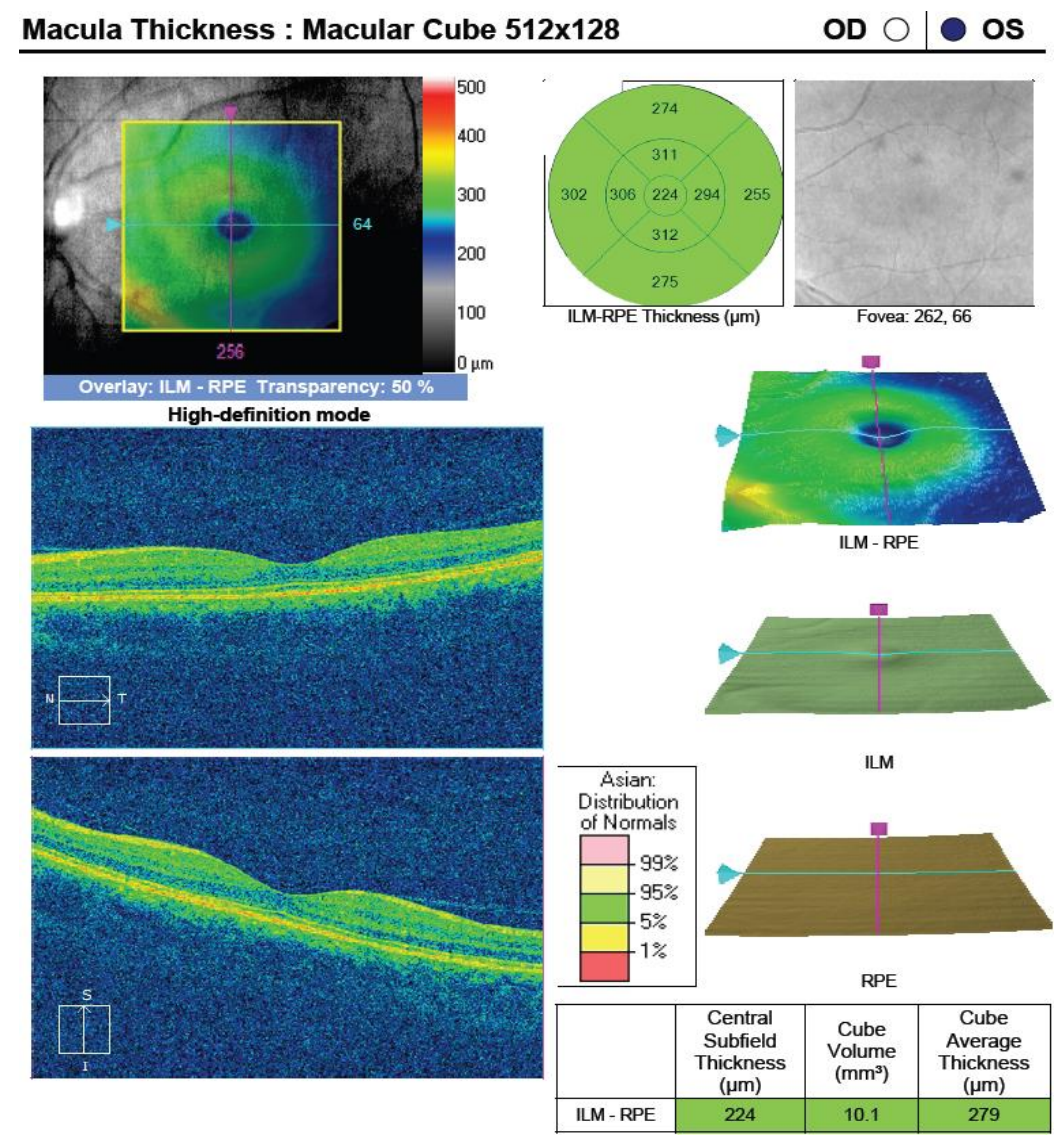

Figure 5. Normal optical Coherence Tomography (OCT) of the right eye (OS)

In our case, we did not perform the visual field examination because our hospital did not have the device. The patient's ophthalmic examination finding was unremarkable, and despite the absence of significant pathologic finding of the right internal carotid on MRA, we found stenosis of right ophthalmic artery due to thromboembolism which might cause ischemia of the retina, leading to
Association recommends admission to a hospital setting. For longer presentation, between 3 to 7 days, hospitalization is still recommended if the patient already had a known untreated source of ischemia (carotid stenosis, atrial fibrillation). ${ }^{10}$ The assessment of vascular risk factors is most important. Patient should be assessed for hypertension, dyslipidemia, diabetes mellitus, 
cardiac disease, and tobacco use. Laboratory studies, electrocardiogram, and neuroimaging studies should be done. ${ }^{4}$ Treatment first aimed at controlling and treating the underlying vascular risk factors.

\section{CONCLUSION}

Amaurosis fugax is caused by an abrupt reduction of blood flow to the retina, with multiple possible etiologies. This case suggests stenosis of ophthalmic artery as the cause of amaurosis fugax. Anticoagulant, antiplatelet, angiotensin receptor blocker, and statin were given and treatment for underlying conditions was maintained. The patient remains under treatment for her hypertension and dyslipidemia, and symptoms had not recurred in the following 6 months after the initial (and only) event.

\section{REFERENCES}

1. Sibel I, Guliz Y, Ubeyt IU. Homocysteinemia as a cause for amaurosis fugax in a patient without an apparent embolic source. Rom J Ophthalmol. 2019;62(2):188-92.

2. Parsons MR, Stoner MC, Doyle A, Mix D, Cameron SJ. Lights out: an unusual case of amaurosis fugax. Am J Med. $2018 \quad$ Feb;131(2):e39-e42. doi: 10.1016/j.amjmed.2017.08.032.

3. Shim DH, Cha JK, Kang MJ, Choi JH, Nah HW. Vasospactic amaurosis fugax diagnosed by cerebral angiography. J Stroke Cerebrovasc Dis. 2015 Nov;24(11):e323-5. doi:0.1016/j.jstrokecerebrovasdis.2015.07.014.

4. Pula JH, Kwan K, Yuen CA, Kattah JC. Update on the evaluation of transient vision loss. Clinical Ophthalmology 2016:10 297-303
5. Adams HP, Putman SF, Corbett JJ: Amaurosis fugax: the results of arteriography in 59 patients. Stroke 1983;14:742-744.

6. Braat $A E$, Hoogland $P H$, de Vries $A C$, van Otterloo AM. Amaurosis fugax and stenosis of the ophthalmic artery. Vascular Surgery 2001;35:141-3.

7. Nakajima M, Kimura K, Minematsu K, Saito K, Takada T, Tanaka M. A case of frequently recurring amaurosis fugax with atherothrombotic ophthalmic artery occlusion. Neurology 2004;62:117-8.

8. Park MS, Kim JT, Lee KR, Lee SH, Choi SM, Kim BC, et al. Recurrent transient monocular blindness with ophthalmic artery stenosis. Eur Neurol 2008;59:2024.

9. Jun, Bokkwan. Diagnostic considerations in patients presenting with transient vision loss. Missouri Medicine. 2017;113(1):63-7.

10. Easton JD, Saver JL, Albers GW, et al. Definition and evaluation of transient ischemic attack: a scientific statement for healthcare professionals from the American Heart Association/American Stroke Association Stroke Councili Council on Cardiovascular Surgery and Anesthesia; Council on Cardiovascular Radiology and Intervention; Council on Cardiovascular Nursing; and the Interdisciplinary Council on Peripheral Vascular Disease. Stroke. 2009; 40(6) 2276-2293.

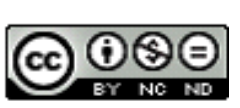

This work licensed under Creative Commons Attribution 